\title{
DETERMINATION OF REGENERATION EFFICIENCY IN DIFFERENT APPLE SPECIES AND VARIETIES
}

\author{
Merve A. Yigit ${ }^{1 *}$, Hasan Pinar ${ }^{1}$, Aydın Uzun ${ }^{1}$ \\ ${ }^{1}$ University of Erciyes, Department of Horticulture, Kayseri, Turkey
}

Current Trends in

Natural Sciences

\begin{abstract}
Genetic transformation technology emerged as a useful tool to shorten the breeding time in plants and also allowed the improvement of the plants by only intended character without changing their other characters. To carry out gene transfer studies, the regeneration efficiency of plants must be known. In this study, in vitro regeneration efficiency was investigated in 9 genotypes in 3 different apple species; Malus domestica, Malus sieversii and Malus niedzwetzkyana. After explants shooted in the media, callus culture was applied to sterile leaves. Genotypes' shoot formation ratio was ranged from $8.33 \%$ to $75 \%$. The genotype with the highest shoot was 'genotype 8', species of M. domestica, with a rate of $75 \%$. Sterile leaves were taken from shoots for callus culture. The regeneration potential of genotypes ranged from $0 \%$ to $90 \%$. While callus formation was not observed in 'genotype 4' and 'genotype 5' (M. domestica), $90 \%$ callus formation was observed in 'genotype 3' (M. domestica). With this study, it has been determined that there is a serious variation in the regeneration efficiency of different apple species and genotypes.
\end{abstract}

Keywords: Apple, Callus culture, Regeneration efficiency

\section{INTRODUCTION}

Conventional clonal propagation methods such as grafting and budding are used successfully by many nursery growers. While successful, these methods are labor intensive and may require large amounts of land and slow. As an alternative, successful in vitro clonal propagation methods are reported in apple for commercial applications in the tree fruit industry (Bommineni et al., 2001). The tissue culture of domesticated apple has an extensive and rich history spanning approximately sixty years (Dobránszki and Teixeira da Silva, 2010). In vitro propagation of apple generally includes 4 stages, as in other plants: (1) in vitro culture establishment from in vivo plants; (2) shoot multiplication and/or regeneration; (3) rooting of microshoots; (4) acclimatization of plantlets and the establishments of plant in an in vivo environment. The most frequently used explants in Stage 1 in apple in vitro propagation are shoot tips or axillary buds when propagated by axillary or terminal buds, or leaves when propagation is based on adventitious shoots (Teixeira da Silva et al., 2019). Genetic transformation in apple depends largely on specific tissue culture techniques that lead to effective regeneration. First, Liu et al., (1983) described this process with lot of explant types from in vitro-grown apple cultures of open-pollinated 'Golden Delicious' seedlings. Then, in addition to studies on apple cultivars, many reports of apple rootstock regeneration and genetic transformation also have been published. Several researchers have used rootstock M.26 for shoot regeneration 
experiments, where in vitro culture of leaves can regenerate shoots at frequencies close to $100 \%$ on a medium based on MS (Murashige and Skoog, 1962) salts, LS vitamins (Linsmaier and Skoog, 1965), containing N6 -benzyladenine (BA), and 1-naphthaleneacetic acid (NAA). They resulted in transformation efficiencies ranging widely from $0.9 \%$ to $80.0 \%$ (Predieri and Malavasi 1989; Norelli et al. 1994; Holefors et al. 1998). Shoot and leaf tissues from Jork 9 rootstock have also served as explant sources. Its transformation efficiency ratio was 3.3\% to 6.5\% (Sedira et al., 2001). Protocols have been developed for regeneration of N545 (Dolgov et al. 1999), M.9/29 (Zhu et al. 2001), and 'Balenghaitang' (Qu et al. 2005) apple rootstocks. Thus, regeneration and transformation efficiencies vary significantly with genotype. Identification of the critical factors that affect these processes is crucial (Zhang et al., 2014).

In this study, in vitro regeneration efficiency was determined in 9 genotypes in 3 different apple species; Malus domestica, Malus sieversii and Malus niedzwetzkyana.

\section{MATERIALS AND METHODS}

Plant material and establishment of culture: Nodal explants were collected in autumn from 5year old mature tree of Malus domestica, Malus sieversii and Malus niedzwetzkyana established in the collection garden of Erciyes University Agricultural Research Center (Turkey). The excised nodal explants $( \pm 1-2 \mathrm{~cm})$ were washed thoroughly under running tap water for $30 \mathrm{~min}$ and then surface-disinfested in $70 \%(\mathrm{v} / \mathrm{v}$ ) ethanol for $30 \mathrm{~s}$. Rinsed three times with sterile distilled water. Then, soaked for $8 \mathrm{~min}$ in a $0.1 \%$ (v/v ) $\mathrm{HgCl}_{2}$ solution. Finally explants rinsed 4 or 5 times in sterile distilled water with duration of 5 min each.four times with sterile distilled water (Dobránszki and Teixeira da Silva 2010). The sterilized single nodal explants were inoculated into test tubes with $15 \mathrm{ml}$ of nutritive solution. The medium contained the mineral salts and vitamins of Murashige and Skoog (1962) supplemented with 6-benzylaminopurine (BAP: $1.0 \mathrm{mg} . \mathrm{L}^{-1}$ ), indole-3-butyric acid (IBA: $\left.0.1 \mathrm{mg} . \mathrm{L}^{-1}\right)$ for shooting, enriched with $30 \mathrm{~g} . \mathrm{L}^{-1}$ sucrose and gelled with agar $\left(8 \mathrm{~g} . \mathrm{L}^{-1}\right)$. The $\mathrm{pH}$ was adjusted to 5.8 with $1 \mathrm{M} \mathrm{NaOH}$ prior to autoclaving at $121^{\circ} \mathrm{C}$ for $20 \mathrm{~min}$ (Boudabous et al., 2010). All explants were cultured at $25^{\circ} \mathrm{C}$ under a $16-\mathrm{h}$ light photoperiod and $50 \mu \mathrm{mol} \mathrm{m}^{-2} \mathrm{~s}$ ${ }^{-1}$ of light intensity from white light (Amoo et al., 2011).

Shoot multiplication: Shoot tips $(1$ to $3 \mathrm{~cm}$ ) obtained from in vitro differentiated shoots were transferred to MS medium supplemented with BAP $\left(2.0 \mathrm{mg} . \mathrm{L}^{-1}\right)$ for induction of multiple shoots. The average number of shoots induced per explants as well as the length of the shoots was recorded each 4 weeks.

Shoot regeneration from leaf explants: Subcultured shoots of 4 week old were used as source material for leaf explants. Healthy, fully expanded young leaves were collected from the subcultured shoots. Leaf blades were cut transversely across the midrib into three or four pieces, or were wounded by crushing the leaf tissue with forceps (Norelli et al., 1996). Explants were placed with their adaxial surface in contact with the medium (MS supplemented with $7.5 \mathrm{~g} \mathrm{~L}^{-1}$ agar, $30 \mathrm{~g}$ $\mathrm{L}^{-1}$ sucrose, $2.3 \mu \mathrm{M}$ TDZ, and $0.9 \mu \mathrm{M}$ NAA) and cultured for 5 wk. Culture conditions included darkness for the first $3 \mathrm{wk}$ followed by $2 \mathrm{wk}$ of light exposure $\left(50 \mu \mathrm{mol} \mathrm{m} \mathrm{m}^{-2} \mathrm{~s}^{-1}\right.$ light intensity). After $3 \mathrm{wk}$ in the dark, a stereomicroscope was used to observe the regeneration events at the time of calli development (Zhang et al., 2014).

\section{RESULTS AND DISCUSSIONS}

Shoot induction: All genotypes from various Malus species (M. niedzwetzkyana, M. sieversii, $M$. domestica) were performed different rates of shoot development. Genotypes' shoot formation ratio 


\section{Current Trends in Natural Sciences}

Vol. 9, Issue 18, pp. 149-153, 2020

https://doi.org/10.47068/ctns.2020.v9i18.020

Current Trends in Natural Sciences (on-line)

ISSN: 2284-953X

Current Trends in Natural Sciences (CD-Rom)

ISSN: 2284-9521

ISSN-L: 2284-9521

ISSN-L: 2284-9521

was ranged from $8.33 \%$ to $75 \%$. The genotype with the highest shoot was 'genotype 8 ', species of M. domestica, with a rate of $75 \%$. This species was followed by the M. niedzwetzkyana and M. sieversii species, respectively for shoot induction with \%58.3 ratio. The lowest shoot development was observed in 'genotype 9' and 'genotype 2'. Leaf explants from 30-day-old in vitro propagated shoots were used for callus induction. Explants produced calli on media depending on hormone concentrations and combinations. Most of the leaf explants showed callus formation after 15 days, producing milky yellow-greenish callus from the edges of the explants on media containing both auxin and cytokinin (Figure 1-D). The regeneration potential of genotypes ranged from $0 \%$ to $90 \%$. Callus formation was not observed in 'genotype 4' and 'genotype 5' (M. domestica) but $90 \%$ callus formation was observed in 'genotype 3' (M. domestica). 'genotype 8' and 'genotype 3 ' has achieved both high rate of shoot growth and callus formation (Table 1). This genotype can be use in genetic transformation studies in apple because of its regeneration efficiency.

Table 1. Effects of different genotypes on shoot and callus induction ratios

\begin{tabular}{cccc}
\hline $\begin{array}{c}\text { Genotype } \\
\text { No }\end{array}$ & Species & $\begin{array}{c}\text { Shoot Induction } \\
\mathbf{\%}\end{array}$ & $\begin{array}{c}\text { Regeneration } \\
\mathbf{\%}\end{array}$ \\
\hline 1 & M. niedzwetzkyana & 50 & 66.6 \\
2 & M. sieversii & 8.33 & 66.6 \\
3 & M. domestica & 50 & $\mathbf{9 0}$ \\
4 & M. domestica & 16.6 & - \\
5 & M. domestica & 58.3 & 33.3 \\
6 & M. domestica & 16.6 & 58.3 \\
7 & M. sieversii & 58.3 & - \\
8 & M. domestica & $\mathbf{7 5}$ & 83.3 \\
9 & M. domestica & 8.33 & 66.6 \\
\hline
\end{tabular}
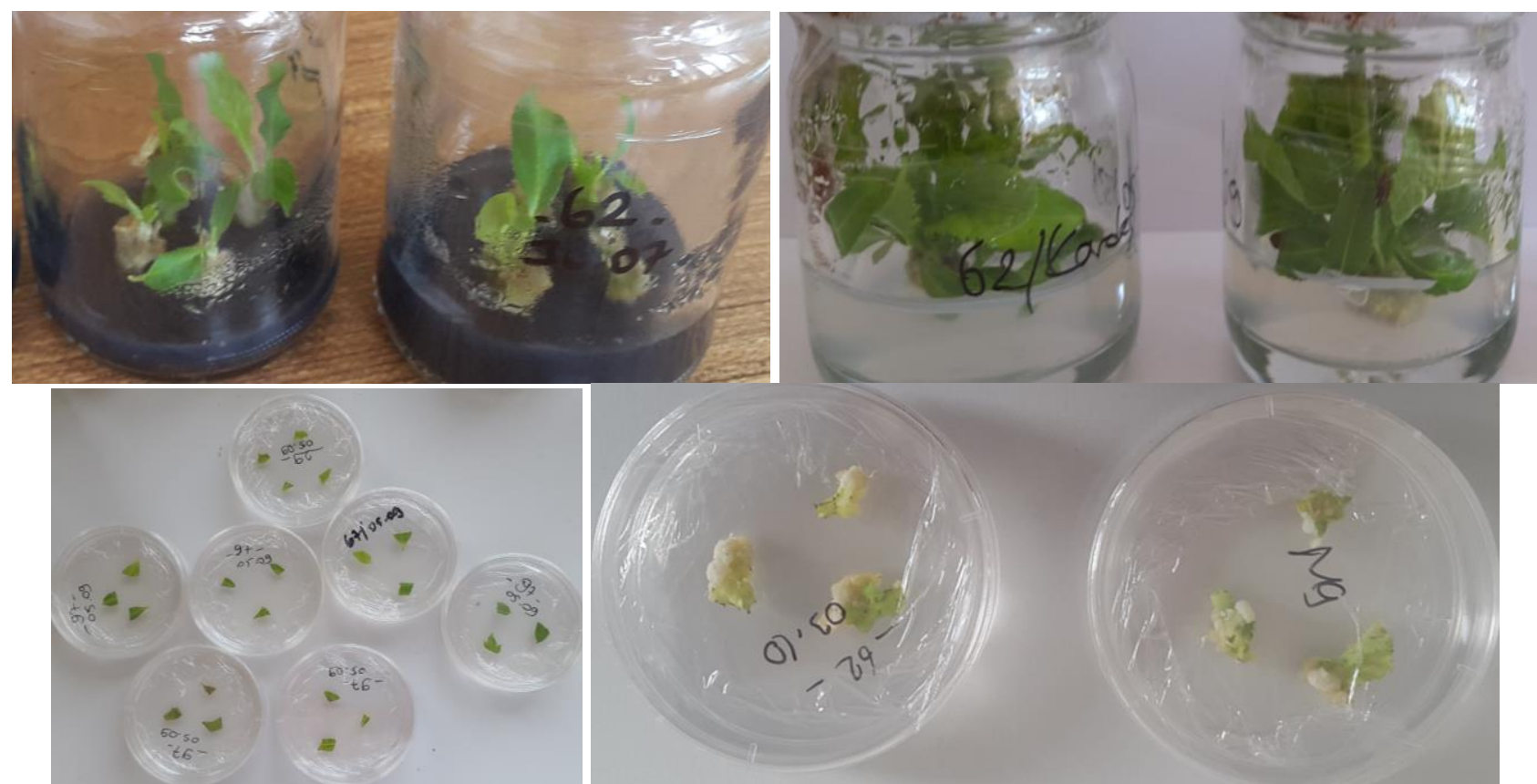

Figure 1. A- Shoot induced from the axillary bud of nodal explant. B-Multiplicated shoots. C-Leaf explants from in vitro shoots D-Regenerated shoots on MS medium supplemented with $2.7 \mu M T D Z$ and $0.9 \mu M N A A$ 
Zhang et al., 2020, aimed to investigate the infuence of diferent concentrations of hormones on wild apple regeneration from leaf and stem explants to establish an optimal regeneration system in their study; An efcient in vitro regeneration system from different wild apple (Malus sieversii) explants. Leaves and stems derived from seedlings were cultured on several media supplemented with various concentrations of TDZ or BA in diferent combinations with NAA. The results showed that the most efcient shoot formation media (35\% and 90\%) were MS medium containing $4.0 \mathrm{mg} \mathrm{L}^{-1}$ TDZ and $1.0 \mathrm{mg} \mathrm{L}^{-1} \mathrm{NAA}$ for leaf explants and MS medium containing $1.0 \mathrm{mg} \mathrm{L}^{-1} \mathrm{BA}$ without NAA for stem explant. MS medium supplemented with $0.4 \mathrm{mg} \mathrm{L}^{-1} \mathrm{BA}$ and $0.1 \mathrm{mg} \mathrm{L}^{-1}$ NAA (for shoot multiplication) and $1 / 2 \mathrm{MS}+0.1 \mathrm{mg} \mathrm{L}^{-1} \mathrm{NAA}+1.5 \%$ sucrose (for rooting) were efective media. Shoot regeneration from leaf explants was the most efective when the explants were placed abaxial side down onto the medium and were subjected to a pre-treatment of 3 weeks in darkness. The genetic diversity and inheritance of BRR and NAB were evaluated using 153 Malus germplasm accessions and 78 hybrid trees of Jonathan $\times$ Golden Delicious. Malus sieversii 31, Liberty, and Smoothee exhibited significantly high BRR $(98.33 \%, 98.33 \%$, and $93.33 \%$, respectively) and a large NAB without vitrification. Bud regeneration rate (BRR) and the number of adventitious buds (NAB) linearly correlated with each other but not with callus formation rate. The broad sense heritability of the regeneration rate was $92.16 \%$. The three Malus accessions that had high regeneration ability, and some of their sexual descendants, might be outstanding genetic resources for future genetic transformation (Tan et al., 2017).

Zhang et al., 2014 determined apple (Malus domestica) rootstock G.41 is an excellent member of the Geneva series because it has traits for resistance to abiotic and biotic stresses. A simple and efficient protocol for obtaining shoots from leaf explants was established by optimizing the combinations of plant growth regulators, mode of wounding, and explant orientation on the culture medium. The best shoot multiplication index (2.58) was obtained from successful subculture medium that was the standard Murashige and Skoog (MS) medium supplemented with $7.5 \mathrm{~g} \mathrm{~L}^{-1}$ agar, $3.55 \mu \mathrm{M}$ N6 -benzyladenine, $0.16 \mu \mathrm{M}$ indole-3-butyric acid, and $30 \mathrm{~g} \mathrm{~L}^{-1}$ sucrose. Regeneration rates were highest (99\%) when MS medium was supplemented with $2.7 \mu \mathrm{M}$ thidiazuron and $0.9 \mu \mathrm{M} 1-$ naphthaleneacetic acid, and cut-wounding explants before placing the abaxial surface in contact with the medium.

A high frequency of sprouting $(85.0 \%)$ and shoot differentiation is observed in the primary cultures of nodal explants of Malus domestica L. cultivar Douce de Djerba on MS medium supplemented with BAP (1.0 mg. $\left.\mathrm{L}^{-1}\right)$ plus IBA $\left(0.1 \mathrm{mg} . \mathrm{L}^{-1}\right)$. In vitro proliferated shoots are multiplied rapidly by culture of shoot tips on MS medium with BAP (1.0 and $\left.2.0 \mathrm{mg} . \mathrm{L}^{-1}\right)$ which produce the greatest multiple shoot formation. The BAP has a positive effect on the multiplication and growth, but a concentration that exceeds $4.0 \mathrm{mg} . \mathrm{L}^{-1}$ decreases the growth (Boudabous et al. 2010).

\section{CONCLUSIONS}

Determination of regeneration efficiency in plants is very important because of reference to gene transfer studies. As seen in this study, the regeneration activities of different apple species and varieties are different from each other. The use of prominent genotypes in terms of regeneration efficiency to be conducted for obtaining transgenic plants will contribute positively to the studies.

\section{REFERENCES}

Amoo, S.O., Finnie, J. F., Van Staden, J. (2011). The role of meta-topolins in alleviating micropropagation problems. Plant Growth Regul 63, 197-206. 
Bommineni, V.R., Mathews, H., Samuel, S.B., Kramer, M., Wagner, D.R. (2001). A New Method for Rapid In Vitro Propagation of Apple and Pear. Hortscience. 36(6), 1102-1106.

Boudabous, M., Mars, M., Marzougui, N., Ferchichi, A. (2010). Micropropagation of apple (Malus domestica L. cultivar Douce de Djerba) through in vitro culture of axillary buds. Acta Bot. Gallica, 157 (3), 513-524.

Dobránszki, J., Teixeira da Silva, J. A. (2010). Micropropagation of apple-a review. Biotechnol Adv 28, $462-488$.

Dolgov, S.V., Morishnichenko, D.N., Schestibratov, K.A. (1999). Agrobacterial transformation of apple cultivar and rootstock. Eucarpia Symp Fruit Breed Genet 538, 619-624.

Holefors, A., Xue, Z.T., Welander, M. (1998). Transformation of the apple rootstock M26 with rolA gene and its influence on growth. Plant Sci. 136, 69-78.

Linsmaier, E.M., Skoog, F. (1965). Organic growth factor requirements of tobacco tissue cultures. Physiol Plant 18, $100-127$.

Liu, J.R., Sink, K.C., Dennis, F.G. (1983). Plant regeneration from apple seedling explants and callus cultures. Plant Cell Tiss Organ Cult. 2, 293-304.

Murashige, T., Skoog, F. (1962). A revised medium for rapid growth and bio assays with tobacco tissue cultures. Physiol Plant. 15: 473-497.

Norelli, J.L., Aldwinckle, H.S., Destéfano-Beltrán, L., Jaynes, J.M. (1994). Transgenic 'Malling 26' apple expressing the attacin E gene has increased resistance to Erwinia amylovora. In: Schmidt H.; Kellerhals M. (eds) Progress in temperate fruit breeding. Kluwer Academic, Dordrecht, The Netherlands, pp 333-338.

Norelli, J., Mills, J., Aldwinckle, H. (1996). Leaf wounding increases efficiency of Agrobacterium-mediated transformation of apple. Hortscience, 31, 1026-1027.

Predieri, S., Malavasi, F.F.F. (1989). High-frequency shoot regeneration from leaves of the apple rootstock M26 (Malus pumila Mill). Plant Cell Tiss Organ Cult. 17, 133-142.

Sedira, M., Holefors, A., Welander, M. (2001). Protocol for transformation of the apple rootstock Jork 9 with the rolB gene and its influence on rooting. Plant Cell Rep. 20, 517-524.

Teixeira da Silva, JA., Gulyás, A., Tábori, K.M., Wang, M.R., Wang, Q.C., Dobránszki, J. (2019). In vitro tissue culture of apple and other Malus species: recent advances and applications. Planta. 249, 975-1006.

Tan, Y., Li, B., Wang, Y., Wu, T., Han, Z., Zhang, X. (2017). Genetic Diversity and Heritability of In Vitro Leaf Regeneration Ability in Malus Species. HortScience, 52(10), 1396-1400.

Qu, S., Huang, X., Zhang, Z., Yao, Q., Tao, J., Qiao, Y., Zhang, J. (2005). Agrobacterium mediated transformation of Malus robusta with tomato iron transporter gene. J Plant Physiol Mol Biol. 31, 235- 240.

Zhang, X., Qin, Y., Liang, D., Zou, Y., Ma, F. (2014). Enhancement of in vitro shoot regeneration from leaf explants of apple rootstock G.41. In Vitro Cell.Dev.Biol._Plant, 50, 263-270. DOI 10.1007/s11627-013-9588-7.7

Zhang, Y., Bozorov, T. A., Li, D. X., Zhou, P., Wen, X. J., Ding, Y., Zhang, D. Y. (2020). An efficient in vitro regeneration system from different wild apple (Malus sieversii) explants. Plant Methods, 16, 1-10.

Zhu, L. H., Holefors, A., Ahlman, A., Xue, Z.T., Welander, M. (2001). Transformation of the apple rootstock M.9/29 with the rolB gene and its influence on rooting and growth. Plant Sci. 160, 433-439. 